\title{
Efeito da substância húmica na germinação de sementes de Myracrodruon urundeuva Fr. All.
}

\section{Effect of humic substance in Myracrodruon urundeuva Fr. All. seed germination}

\author{
Alexandre Ribeiro da Mota ${ }^{1}$, Rodrigo José da Silva ${ }^{2}$, Priscila Bezerra de Souza ${ }^{3}$, Lucicléia Mendes de Oliveira ${ }^{4}$, Antônio \\ Carlos Martins dos Santos ${ }^{5}$
}

\begin{abstract}
Resumo - As substâncias húmicas originam-se da oxidação e polimerização da matéria orgânica, apresentando elevadas massas moleculares e variados grupos funcionais. Dependendo da solubilidade em meio aquoso, as substâncias húmicas são divididas em ácido húmico, ácido fúlvico e humina. São poucas pesquisas relacionadas aos efeitos das substâncias húmicas na germinação de sementes, e não foram encontrados trabalhos utilizando a espécie Myracrodruon urundeuva Fr. All. A composição das substâncias húmicas é variada, isso dificulta o entendimento de seu efeito. O objetivo da pesquisa foi analisar o efeito de diferentes concentrações de substâncias húmicas na germinação de sementes de Myracrodruon urundeuva Fr. All. O trabalho foi desenvolvido no laboratório de sementes da Universidade Federal do Tocantins, no qual as sementes ficaram imergidas por 12 horas em solução contendo concentrações de 0,$00 ; 0,25 ; 0,50 ; 0,75$ e 1,00\% de substância húmica, posteriormente foram colocadas para germinar em B.O.D regulada a $25^{\circ} \mathrm{C}$. Sendo avaliadas através das medidas porcentagem, tempo médio e índice de velocidade de germinação. A aplicação de substâncias húmicas nas concentrações entre 0 e $0,25 \%$ pode promover efeito positivo sobre a germinação e o índice de velocidade de germinação de sementes de Myracrodruon urundeuva Fr. All e as concentrações maiores causam efeito fitotóxico.
\end{abstract}

Palavras-chaves: Ácidos Húmicos, desempenho, medidas de germinação, fitotoxidez

\begin{abstract}
Humic substances are originated from the oxidation and polymerization of the organic matter, with high molecular weights and diverse functional groups. Depending of the solubility aqueous environment humic substances are divided in humic acid, fulvic acid and humin. There are few researches related to the humic substances effects on seeds germination, and were not found researches using species Myracrodruon urundeuva Fr. A11. Humic substances compositions are varied that makes it hard to understand its effects. The work intended to analyse the effects of different concentrations of humic substances on Myracrodruon urundeuva Fr. All seed germination. The work was developed in the seed laboratory in the Federal University of Tocantins, where the seeds were kept emerged for 12 hours within a solution containing $0.00 ; 0.25 ; 0.50$; 0.75 and $1.00 \%$ of humic substance concentration, were subsequently germinated in B.O.D regulated at $25^{\circ} \mathrm{C}$. These samples have been evaluated by percentage measures, average time and germination speed index. Humic substances application in concentration 0 and $0.25 \%$ might provide positive effect on germination and on Myracrodruon urundeuva Fr. All. seeds germination speed index and higher concentrations cause phytotoxic effect.
\end{abstract}

Key words: Humic Acid, performance, germination measures, phytotoxicity

\footnotetext{
*Autor para correspondência

Recebido para publicação em 02/07/2015; aprovado em 08/08/2015

${ }^{1}$ Mestrando em Ciências Florestais e Ambientais, Universidade Federal do Tocantins, E-mail: armota@ hotmail.com

${ }^{2}$ Professor do Instituto Federal de Educação, Ciência e Tecnologia do Tocantins, E-mail: rodrigo.silva@ifto.edu.br

${ }^{3}$ Professora do Programa de Pós-Graduação em Ciências Florestais e Ambientais, Universidade Federal do Tocantins, E-mail: priscilauft@uft.edu.br

${ }^{4}$ Bolsista PNPD da Pós-Graduação em Ciências Florestais e Ambientais, Universidade Federal do Tocantins, E-mail: lucicleia@ biologa.bio.br

${ }^{5}$ Doutorando em Produção Vegetal, Universidade Federal do Tocantins, E-mail: antoniocarlos.uft@hotmail.com
} 


\section{INTRODUÇÃO}

A Aroeira-do-Sertão (Myracrodruon urundeuva Fr. All.) pertencente à família Anacardiaceae, é uma espécie decídua, heliófila e seletiva xerófita, nativa do Brasil, apresentando distribuição ampla pelo território brasileiro com ocorrência na Região Nordeste, Centro-Oeste e Sudeste, sendo encontrada também na região chaquenha da Bolívia, Paraguai e Argentina (TSUKAMOTO FILHO et al., 2013).

A aroeira possui grande importância em razão do aproveitamento da madeira, da farmacologia e da extração de taninos (CARLINI et al., 2010 citado por SCALON et al., 2012). Os usos da madeira são múltiplos, especialmente na construção civil por apresentar resistência aos microorganismos e grande resistência mecânica. Tendo em vista a importância da espécie, estudo sobre meios que possibilitem a germinação da forma mais rápido se fazem necessários.

De acordo com Ferreira e Borghetti (2004) a germinação acontece em fases, em que as principais etapas são: embebição de água (reidratação), aumento da respiração, alongamento das células, divisão celular (consequente formação de enzimas, digestão, mobilização e transporte das reservas e assimilação metabólica), crescimento e diferenciação dos tecidos. E para que a germinação ocorra de maneira eficiente é necessário que o meio possua temperatura adequada, oxigênio e umidade, as quais irão influenciar diretamente na ativação das reações químicas relacionadas ao metabolismo e, com isto retomar o processo de desenvolvimento do embrião

Para avaliar o potencial de germinação das sementes são realizados testes em laboratório utilizando condições ideais e metodologias adequadas conforme a espécie (BRASIL, 2009), no entanto, apenas o teste de germinação não é suficiente para expressar o potencial fisiológico de um lote de sementes, por isso, são também realizados testes de vigor como: primeira contagem, velocidade de germinação, comprimento e massa seca de plântulas. Dentre os fatores que regulam esse processo fisiológico, a presença de hormônios e o equilíbrio entre os promotores e inibidores de crescimento exercem papel fundamental para dar início à germinação das sementes (FERREIRA; BORGHETTI, 2004).

Para acelerar e melhorar a germinação de sementes e também promover o crescimento das plantas jovens, vários pesquisadores sugerem o uso de reguladores vegetais (WEBER, 2011; NICCHIO et al., 2013). Tem-se observado que a substância húmica proporciona aumento no número de mitoses e raízes laterais de plântulas de milho (AGUIAR et al., 2009), partindo dessa premissa acredita-se que tal substância pode acelerar o processo de germinação das sementes.

Adicionalmente, Petrovic et al. (1982) observaram ação da substância húmica sobre as plantas semelhante às auxinas e também isolaram ácidos húmicos que apresentaram efeitos semelhantes à giberelinas em rabanete (Raphanus sativus L.).

As substâncias húmicas $(\mathrm{SH})$ se dividem em ácidos húmicos, ácidos fúlvicos e humina. O ácido húmico é a fração escura extraída geralmente em meio alcalino e insolúvel em meio ácido (PICCOLO et al., 1996b). A humina é a fração insolúvel tanto no meio alcalino como no meio ácido e os ácidos fúlvicos são frações coloridas alcalino-solúvel que se mantêm em solução após a remoção dos ácidos húmicos por acidificação e possuem maior conteúdo de grupos funcionais ácidos. As substâncias húmicas são compostas por oxigenados, principalmente carboxílicos $(\mathrm{COOH})$, hidroxilas $(\mathrm{OH})$, carbonilas $(\mathrm{C}=\mathrm{O})$, metóxilas $(\mathrm{OCH} 3)$ e ocasionalmente ésteres (COOR) e éteres (COC) (HAYES et al., 1989). Pode ser extraída facilmente de carvão mineral, apresentando eficiência no desenvolvimento de diversas culturas (XUDAN, 1986).

Os efeitos da aplicação das substâncias húmicas na germinação e na qualidade fisiológica das sementes tem sido relatado em trabalhos recentes com Leucena (BALDOTTO et al., 2013) e culturas anuais como soja (WEBER, 2011) e sorgo (VENDRUSCULO et al., 2014). Diante do exposto, a presente pesquisa teve por objetivo avaliar o efeito da substância húmica na germinação de sementes de Myracrodruon urundeuva Fr. All. quando submetidas à embebição sob diferentes concentrações.

\section{MATERIAL E MÉTODOS}

O estudo foi desenvolvido no laboratório de sementes da Universidade Federal do Tocantins - UFT, Campus Universitário de Gurupi, Estado do Tocantins, localizada nas coordenadas geográficas, latitude de $11^{\circ} 43^{\prime} \mathrm{S}$, longitude de $49^{\circ} 04^{\prime} \mathrm{O}$ e altitude de 280 metros. Segundo a classificação de Köppen, o clima da região é Aw, definido como tropical quente e úmido com estação chuvosa no verão e seca no inverno.

As sementes de Myracrodruon urundeuva Fr. All.foram colhidas no município de Formoso do Araguaia (TO), em oito de março de 2014, em seguida enviadas para o laboratório de sementes da UFT, Campus de Gurupi, onde foram beneficiadas e acondicionadas em embalagem de vidro, permanecendo armazenadas na temperatura de $20{ }^{\circ} \mathrm{C}$ até a instalação do experimento, em 27 de junho de 2014.

Inicialmente as sementes foram desinfestadas com hipoclorito de sódio 5\%, durante 5 minutos, e em seguida lavadas com água destilada. As sementes foram imersas por 12 horas em solução contendo substância húmica com diferentes concentrações, constituindo os seguintes tratamentos pré-germinativos: T1 - embebição em água destilada; T2 - embebição na concentração de 0,25\%; T3 embebição na concentração de $0,50 \%$; T4 - embebição na concentração de $0,75 \%$ e T5 - embebição na concentração de $1,00 \%$, cujos tratamentos foram constituídos por quatro repetições de 25 sementes cada, totalizando 100 sementes por tratamento.

Após a imersão das sementes, estas foram colocadas sobre papel germitest ${ }^{\circledR}$ previamente umedecido com água destilada na quantidade equivalente a 2,5 vezes o peso do papel seco e mantido em germinador tipo B.O.D regulado á temperatura de $25{ }^{\circ} \mathrm{C}$ constante com fotoperíodo de 12 horas, utilizando-se lâmpadas fluorescentes tipo luz do dia (4 x 20 W). Foi adotado o critério botânico de germinação sendo consideradas germinadas as sementes que apresentam radícula com $1 \mathrm{~cm}$.

As avaliações foram feitas através das medidas da porcentagem, tempo médio e índice de velocidade de germinação sendo calculados por meio das fórmulas citadas por Labouriau e Valadares (1976) e Maguire (1962):

- Porcentagem de germinação: $G=(N / A) .100$ 
onde: $\mathrm{G}=$ porcentagem de germinação; $\mathrm{N}=$ número de sementes germinadas; $\mathrm{A}=$ número total de sementes colocadas para germinar

- Tempo médio de germinação: $\mathrm{t}=(\Sigma$ niti $) / \Sigma$ ni $)$

onde: $\mathrm{TMG}=$ Tempo Médio de Germinação; ni= número de sementes germinadas por dia; ti = tempo de incubação (dias)

-Índice de Velocidade de Germinação: IVG $=\mathrm{G} 1 / \mathrm{N} 1+$ $\mathrm{G} 2 / \mathrm{N} 2+\ldots \mathrm{Gn} / \mathrm{Gn}$

onde: IVG = Índice de Velocidade de Geminação. G1, $\mathrm{G} 2, \ldots \mathrm{Gn}=$ número de sementes germinadas na primeira contagem, na segunda contagem e na última contagem. N1, $\mathrm{N} 2, \ldots \mathrm{Nn}=$ número de dias da semeadura à primeira, segunda e última contagem.

$\mathrm{O}$ delineamento utilizado foi inteiramente casualizado sendo composto por cinco tratamentos pré-germinativos distribuídos em quatro repetições de 25 sementes cada. Os dados foram submetidos à análise de variância pelo teste $\mathrm{F}$ e as médias comparadas pelo teste de Scott-Knott a $5 \%$ de probabilidade.

\section{RESULTADOS E DISCUSSÃO}

A germinação das sementes Myracrodruon urundeuva Fr. All. distribuiu-se de forma distinta nos diferentes tratamentos, sendo que a concentração de $0,25 \%$ de substância húmica proporcionou maior resultado em termos de valores, no entanto, não apresentou diferença significativa comparativamente as sementes não tratadas e essa tendência também é constatada para o índice de velocidade de germinação (Tabela 1). Enquanto as demais concentrações $(0,50 ; 0,75$ e $1,00 \%)$ na qual as sementes ficaram emersas condicionaram efeitos negativos prejudicando tanto a porcentagem quanto a velocidade de germinação das sementes.

Tabela 1. Avaliação da porcentagem de germinação, índice de velocidade de germinação e tempo médio de germinação de sementes de Aroeira-do-Sertão (Myracrodruon urundeuva Fr. All.)

\begin{tabular}{ccll}
\hline Tratamentos & Germinação (\%) & IVG & TMG \\
\hline $0,00 \%$ & $38^{\mathrm{a}}$ & $2,09 \mathrm{a}$ & $4,80 \mathrm{a}$ \\
$0,25 \%$ & $48^{\mathrm{a}}$ & $2,58 \mathrm{a}$ & $5,03 \mathrm{a}$ \\
$0,50 \%$ & $30 \mathrm{~b}$ & $1,49 \mathrm{~b}$ & $5,55 \mathrm{a}$ \\
$0,75 \%$ & $28 \mathrm{~b}$ & $1,58 \mathrm{~b}$ & $4,78 \mathrm{a}$ \\
$1,00 \%$ & $18 \mathrm{c}$ & $0,94 \mathrm{~b}$ & $5,21 \mathrm{a}$ \\
CV $(\%)$ & 20,41 & 23,20 & 7,74 \\
\hline
\end{tabular}

Médias seguidas da mesma letra na coluna não diferem entre si pelo teste de Scott-Knott a $1 \%$ de probabilidade de erro.

Diferentemente dos resultados do presente trabalho, Oliveira et al. (2013) concluíram em seus estudos que o efeito do tratamento com ácido húmico em sementes de Leucena, previamente escarificada ou não com ácido sulfúrico, não foi significativo para a característica germinação de sementes. Devido a esses resultados encontrados, os autores relatam sobre a necessidade de mais estudos testando o tempo de contato, a concentração e as condições do meio para garantir maior eficiência.

Já Vendrusculo et al. (2014) trabalhando com sementes de duas variedades de sorgo granífero (1G282 e 50a50) sob tratamento de $\operatorname{Humykos}^{\circledR}$, produto à base de substâncias húmicas, observaram que não houve efeito das doses de substâncias húmicas na germinação e no crescimento inicial de plântulas de sorgo. Entretanto, houve diferença entre as duas variedades testadas, sendo a variedade 50a50 superior para as características índice de velocidade de emergência, germinação e emergência.

Em relação ao índice de velocidade de germinação (IVG), quanto maior o valor desta característica maior a germinação média diária, teoricamente alcançando o valor máximo quando todas as sementes germinam no primeiro dia, sendo assim o valor máximo de IVG é de acordo com o número total de sementes germinadas por dia. Sendo os melhores valores de IVG observado nas concentrações $0 \%$ e $0,25 \%$ (Tabela 1).

Segundo WEBER (2011) sementes com alto potencial fisiológico são capazes de germinar uniforme e rapidamente sob ampla variação do ambiente podendo ser caracterizadas pelo teste de velocidade de germinação, de modo que a emergência tardia de plântulas reflete no menor vigor. Nesse sentido, sementes de Myracrodruon urundeuva Fr. All. germinadas sob concentração entre 0 e $0,25 \%$ de substâncias húmicas apresentariam maior vigor.

O tempo médio de germinação (TMG) não apresentou diferença significativa entre os tratamentos (Tabela 1). Quanto maior o valor indica que as sementes germinaram mais no final do período avaliado, teoricamente atingindo o valor máximo quando as sementes germinam no último dia de avaliação, sendo assim o valor máximo do TMG é o número de dias de avaliação.

O TMG e o IVG não devem ser avaliados isoladamente, pois ambos podem apresentar falhas, como por exemplo, apresentar o mesmo valor sob condições diferentes, isso vai depender da quantidade de sementes germinadas e da distribuição destas ao longo do período avaliado. Neste caso, para analisar os dados com maior precisão é necessário avaliar o máximo de variáveis possíveis.

O efeito negativo nos parâmetros germinação e IVG é notado à medida que se aumenta a concentração de substância húmica na solução, sugerindo que a concentração ideal de substância húmica esteja entre 0 e $0,25 \%$. Esse resultado negativo pode ser explicado pelo exposto por Camargo et al. (2001) em que, segundo os autores, alguns ácidos orgânicos podem provocar fitotoxidez limitando a germinação e o desenvolvimento das plantas. De acordo com esses mesmos autores a fitotoxidez está diretamente relacionada ao $\mathrm{pH}$, comprimento da cadeia de carbonos e concentração dos ácidos no meio em que se encontram. Estando os principais efeitos associados à inibição da germinação e da expansão radicular, como resultado de lesões causadas ao tecido meristemático da radícula ou de limitações à respiração, conduzindo à inibição da divisão celular.

Apesar de não ter sido avaliado neste estudo o crescimento das plantas, alguns autores relatam que as substancias húmicas podem ainda influenciar no crescimento e desenvolvimento vegetal, alterando diretamente o metabolismo bioquímico das plantas (ROSA et al., 2009) e afetando a permeabilidade das membranas através das bombas de prótons, contribuindo assim para uma maior absorção de nutrientes (ZANDONADI et al., 2014).

$\mathrm{O}$ uso de substâncias húmicas têm demonstrado alterações diversas no desenvolvimento de algumas culturas alterando aspectos como fisiologia, absorção de nutrientes e metabolismo. Segundo diversos autores (PICCOLO et al., 
1996a; PICCOLO et al., 1996b; SIMPSON, 2002) as substâncias húmicas se comportam como uma associação supramolecular de moléculas relativamente pequenas e heterogêneas, unidas pela ação de forças fracas dispersivas, que podem ser rompidas pela adição de ácido. Essas substâncias são resultantes da agregação de várias classes de compostos orgânicos, como açúcares, aminoácidos, ésteres, éteres alifáticos e aromáticos (PICCOLO et al., 2003). Características como essas conferem às substâncias húmicas uma interação dinâmica e complexa com as plantas, sendo necessário estudos mais aprofundados afim de determinar suas ações na germinação de sementes, bem como concentração ideal, tempo de contato, condição do meio, $\mathrm{pH}$ e fitohormônios potencializadores da germinação e crescimento de plantas.

\section{CONCLUSÕES}

A aplicação de substâncias húmicas na concentração entre 0 e $0,25 \%$ pode promover efeito positivo sobre a germinação e o índice de velocidade de germinação de sementes de Myracrodruon urundeuva Fr. All.

Soluções de substâncias húmica nas concentrações 0,50; 0,75 e $1,00 \%$ promovem efeito fitotóxico sobre a germinação e o índice de velocidade de germinação de sementes de Myracrodruon urundeuva Fr. All.

\section{REFERÊNCIAS BIBLIOGRÁFICAS}

AGUIAR, N. O.; CANELlAS, L. P.; DOBBSS, L. B.; ZANDONADI, D. B.; OLIVARES, F. L.; FAÇANHA, A. R. Distribuição de massa molecular de ácidos húmicos e promoção do crescimento radicular. Revista Brasileira de Ciência do Solo, Viçosa, v.33, n.6, p.16131623, 2009.

BAldotTO, M. A.; GOBO, A. A. R.; SALOMÃO, M. S. M. B.; REZENDE, C. E.; CAMARGO, P. B. Frações da matéria orgânica e propriedades redox de substâncias húmicas em sedimentos de oceanos profundos. Química Nova, São Paulo, v.36, n.9, p.1288-1295, 2013.

BRASIL. Ministério da Agricultura, Pecuária e Abastecimento. Regras para Análise de sementes. Secretária de Defesa Agropecuária. Brasília: MAPA/ACS, 2009. 395p.

CAMARGO, F. A. O.; ZONTA, E.; SANTOS, G. A.; ROSSIELlO, R. O. P. Aspectos fisiológicos e caracterização da toxidez de ácidos orgânicos voláteis em plantas, Ciência Rural, Santa Maria, v.31, n.3, p.223229, 2001.

FERREIRA, A. G.; BORGHETTI, F.; Germinação: do básico ao aplicado. Artmed: Porto Alegre, 2004, 324p.

HAYES, M. H. B. MACCARTHY, P. MALCOLM, R. L. SWIFT, R. S. Humic Substances II. In: Search of Structure. West Sussex, UK: John Wiley e Sons Ltd. 1989. 733p.

LABOURIAU, L. G.; VALADARES, M. E. B. On the germination of seeds Calotropis procera (Ait.) Ait.f.
Anais da Academia Brasileira de Ciências, Rio de Janeiro. v.48, n.2, 1976. p.263-284.

MAGUIRE, J. D. Speed of germination-aid in selection and evaluation for seedlings emergence and vigor. Crop Science, Madison, v.2, n.1, p.176-177, 1962.

NICCHIO, B.; BOER, C. A.; SIQUEIRA, T. P.; VASCONCELOS, A. C. P.; REZENDE, W. S.; LANA, R. M. Q.; Ácido húmico e bioativador no tratamento de sementes de milho. Journal of Agronomic Sciences, Umuarama, v.2, n.2, p.61-73, 2013.

OLIVEIRA, A. C. G.; BALDOTTO, M. A.; DEL GIUDICE, M. P.; BALDOTTO, L. E. B. Germinação de sementes de Leucaena leucocephala escarificadas ou não com ácido sulfúrico em resposta ao tratamento com ácidos húmicos. In: IV CONGRESSO BRASILEIRO DE GESTÃO AMBIENTAL. Salvador - BA, 2013.

PETROVIC, P.; VITOROVIC, D.; JABLANOVIC, M. Investigations of biological effects of humic acids, Acta Biological Medical Experimental, Budapest, v.7, p.2125,1982 .

PICCOLO, A.; CONTE, P.; SPACCINI, R.; CHIARELLA, M. Effects of some dicarboxilic acids on the association of dissolved humic substances, Biology and Fertility of Soils, [s.1], v.37, p.255-261, 2003.

PICCOLO, A.; NARDI, S.; CONCHERI, G. Macromolecular changes of humic substances induced by interaction with organic acids. European Journal of Soil Science, [s.1], v.47: p.319-328, 1996 .

PICCOLO, A.; NARDI, S.; CONCHERI, G. Micelle-like conformation of humic substances as revealed by size exclusion chromatography. Chemosphere, [s.1.], v.33, n.4, p.595-602, 1996 b.

ROSA, C. M.; CASTILHOS, R. M. V.; VAHL, L. C.; CASTILHOS, D. D.; PINTO, L. F. S.; OLIVEIRA, E. S.; LEAL, O. A. Efeito de substâncias húmicas na cinética de absorção de potássio, crescimento de plantas e concentração de nutrientes em Phaseolus vulgaris L. Revista Brasileira de Ciência do Solo, Viçosa, v.33, n.4, p.959-967, 2009.

SCALON, S.P.Q.; SCALON FILHO, H.; MASETTO, T.E. Aspectos da germinação e desenvolvimento inicial de plântulas de aroeira. Cerne, Lavras, v.18, n.4, p.533-539, 2012.

SIMPSON, A. J. Determining the molecular weight, aggregation, structures and interactions of natural organic matter using diffusion ordered spectroscopy. Mag. Reson. Chem., [s.1], v.40, p.572-592, 2002.

TSUKAMOTO FILLHO, A. A; BRONDANI, G. E.; CARVAlHO, J. L. O.; COSTA, R. B.; DALMOLIN, A. C. Regime de regas e cobertura de substrato afetam o crescimento inicial de mudas de Myracrodruon 
urundeuva. Floresta e Ambiente, Rio de Janeiro, v.20, n.4, p.521-529, 2013.

VENDRUSCOLO, E. P.; SANTOS, O. F.; ALVES, C. Z. Substâncias húmicas na qualidade fisiológica de sementes de sorgo, Journal of Agronomic Sciences, Umuarama, v.3, n.2, p.169-177, 2014.

WEBER, F. Uso de bioestimulantes no tratamento de sementes de soja. Pelotas, 2011. 28f. Dissertação (Mestrado em Ciências). Faculdade de Agronomia Eliseu Maciel, Universidade Federal de Pelotas, 2011.
XUDAN, X. The effect of foliar application of fulvic acid on water use, nutrient uptake and yield in wheat. Australian Journal of Agricultural Research, Meulbourne, v.37 n.2, p.343-350, 1986.

ZANDONADI, D. B; SANTOS, M. P; MEDICI LO; SILVA J. Ação da matéria orgânica e suas frações sobre a fisiologia de hortaliças. Horticultura Brasileira, [s.l], v.32, n.1, p.14-20, 2014. 